\title{
Pandemic COVID-19 and Biomedical Waste Handling: A Review Study
}

\author{
Authors
Dr Irin Hossain**1, Dr Ashekur Rahman Mullick², Dr Shazly Bari ${ }^{3}$, Mohammad Tahsin Islam 4 \\ ${ }^{1}$ National Institute of Preventive and Social Medicine (NIPSOM), Dhaka, Bangladesh \\ ${ }^{2}$ Delta Medical College and Hospital, Dhaka, Bangladesh \\ ${ }^{3}$ Directorate General of Health Services (DGHS), Dhaka, Bangladesh \\ ${ }^{4}$ Gerico France, Paris, France \\ *Corresponding Author \\ Dr Irin Hossain
}

\begin{abstract}
This review study aims at discussing the linkage between COVID-19 and biomedical waste management. The ongoing COVID-19 pandemic has already turned healthy places around the world into a living hell with massive death tolls because of its fastest-spreading nature, and continuously leading to lockdowns in almost every part of the world. Amid all the problems so far it created, one significant problem that can create major havoc in this already devastating and contagious atmosphere in a densely populated city is, not handling medical waste properly. It was a systemic review study regarding the relationship between COVID-19 and biomedical waste management. We have gathered total 26 articles and newsletters related to COVID-19 and biomedical waste management using different search portal like PubMed, Google Scholar, Nature, and Lancet. After proper literature review only 12 articles and newsletters which were related to this study were taken for this systemic review purpose. If the massive amount of medical wastages cannot be managed through maintaining proper and adequate guidelines, chances of community-based spreading of COVID-19 can exceed the limit and take more lives in the upcoming days.

Keywords: Biomedical waste management, Pandemic COVID-19.
\end{abstract}

\section{Introduction}

According to the Medical Waste (Management and Processing) Rules 2008, "medical wastes could not be mixed with other wastes at any stage while producing inside hospitals, while collecting from hospitals, while transporting, and would be processed separately based on classification". The ongoing COVID-19 pandemic has already turned healthy places around the world into a living hell with massive death tolls because of its fastestspreading nature, and continuously leading to lockdowns in almost every part of the world. Amid all the problems so far it created, one significant problem that can create major havoc in this already devastating and contagious atmosphere in a densely populated city is not handling medical waste properly. China's Wuhan, the first of the cities that got viciously brutalised by the pandemic, is home to 11 million people. Its hospitals produced more than 240 tonnes of medical waste daily during the peak of the outbreak compared with 40 tonnes before the epidemic occurred, according to China's Ministry of 
Ecology and Environment's emergency office. To fight this enormous amount of medical wastages, the central government deployed 46 mobile medical waste treatments facilitates to the city of Wuhan and built a new plant with a capacity of 30 tonnes within 15 days in March. Biomedical wastes are hazardous because they host potential virus particles that can be hidden beneath human tissues, items contaminated with blood bags, needles, syringes or any other sharp object, body fluids-remaining like dressings, plaster casts, cotton swabs, beddings contaminated with blood or body fluid etc. Experts say medical wastages are not like other wastes such as the household or industrial wastages. It can infect one directly through the skin or by ingestion and inhalation with objects like inhalers or ventilating pipes. Many contagious viruses including HIV and Hepatitis ( $\mathrm{B}$ and $\mathrm{C}$ ) can easily be generated from such wastes and can harm the ones who do not have the diseases. Germs and viruses, which are antibiotic-resistant (such as the COVID-19 at this point) can easily spread from medical waste. Biomedical wastes are hazardous because they host potential virus particles that can be hidden beneath human tissues, items contaminated with blood bags, needles, syringes or any other sharp object, body fluids-remaining like dressings, plaster casts, and cotton swabs, beddings contaminated with blood or body fluid etc. ${ }^{1}$.

The safe management of household waste is also likely to be critical during the COVID-19 emergency. Medical waste such as contaminated masks, gloves, used or expired medicines, and other items can easily become mixed with domestic garbage, but should be treated as hazardous waste and disposed of separately. These should be separately stored from other household waste streams and collected by specialist municipality or waste management operators ${ }^{2}$.

Healthcare facilities should continue to handle infectious waste following medical waste management procedures. At this time, there are no indications that the presence of the Corona virus at a healthcare facility will create new infectious waste streams requiring special handling. For instance, hospital waste such as disinfecting wipes, personal protective equipment, or disposable food ware may be disposed of as solid waste in the trash. Per usual guidance, all non-recyclable wastes from households and hospitals should be bagged and tied before placed in a trash receptacle. All of these wastes should be disposed of in a solid waste landfill permitted to accept municipal solid waste ${ }^{3}$.

\section{Materials and Methods}

It was a systemic review study regarding the relationship between COVID-19 and biomedical waste management. We gather total 26 articles and newsletters related to COVID-19 and biomedical waste management using different search portal like PubMed, Google Scholar, Nature, and Lancet. After proper literature review only 12 articles and newsletters which were related to this study were taken for this systemic review purpose.

\section{Results}

In Bangladesh, as of April 24, the government has distributed 12,50,000 PPE sets to hospitals. These sets, when used, will produce approximately $18,70,000$ kilograms of hazardous medical waste. More use of PPE will produce more medical waste, meanwhile health care workers are also using PPE that are not part of government supplies. PPE comprises of cover-all (the gown for covering the body), long foot cover, face mask, a pair of hand gloves, mask, goggles and face shield. All these components are one time use, except the goggles and face shield, which experts opine may be reused following standard disinfecting procedure. However, the other components of PPE have no scope of reuse, and they have to be discarded according to standard protocols to ensure the safety of physicians, nurses and technicians. One NGO in Dhaka has stepped up to this waste management job. They collect medical waste from hospitals and clinics in open drums and transport them to disposal sites in covered vans. Medical waste is then treated in a plant in Matuail Landfill in Dhaka South City Corporation. The facility, although not modern, is the only option for the people of Dhaka-located $27 \mathrm{~km}$ from Kuwait 
Bangladesh Friendship Government Hospital in Uttara. However, unsealed collection and transportation of Covid-19 waste over such long distances is certainly dangerous, and medical waste workers are also unwilling to handle this waste ${ }^{4}$.

Untreated medical wastes are accumulating at landfills in seven divisional cities, posing seriousthreat to public health. These divisional cities, excluding the capital, have around 1,380healthcare establishments -- public and private -- which produce over 20 tons of medical wastes every day. Although there have been many reports on the same scenario in Dhaka city,the other divisional cities have often escaped scrutiny in this regard. But the picture there is also quite alarming.According to experts, medical waste is not like other wastesand it can infect through the skin, as well as through inhalation or ingestion. They said HIV, and Hepatitis B and C present the greatest risk from such waste. Besides, antibiotic resistant germs(superbugs) and other dangerous germs can spread from medical waste ${ }^{5}$.

Moreover, since medical wastes can infect through contact with the skin and through inhalation or ingestion, those who collect and sort out the waste are in extreme risk of getting infected with various life-threatening diseases. Amid such a situation, it is extremely disappointing to learn that the country has only one medical waste treatment plant located in Dhaka ${ }^{6}$.

In India, the Central Pollution Control Board (CPCB) has recently released specific guidelines for handling and safe disposal of biomedical waste generated during the diagnosis, treatment and quarantine period of patients confirmed or suspected to have the COVID-19. Though the country already had Bio-Medical Waste Management Rules (formed in 2016), the new CPCB guidelines were released to ensure that the waste generated specifically during testing of people and treatment of COVID-19 patients is disposed of in a scientific manner ${ }^{1}$.

In Wuhan, where the novel coronavirus first emerged, officials didn't just need to build new hospitals for the influx of patients; they had to construct a new medical waste plant and deploy 46 mobile waste treatment facilities too. Hospitals there generated six times as much medical waste at the peak of the outbreak as they did before the crisis began. The daily output of medical waste reached 240 metric tons, about the weight of an adult blue whale ${ }^{7}$.

\section{Discussion}

\section{Government instruction regarding waste management during COVID-19:}

1. Ensure collection and treatment of healthcare waste

2. Ensure the collection and treatment of household waste

3. Maintain in operation incineration and land filling for non-hazardous waste

4. Maintain in operation hazardous waste treatment

5. Maintain as long as possible the separate collection of household waste (packaging, paper, cardboard, glass)

6. Maintain as long as possible in operation the sorting facilities for separately collected household waste ${ }^{8}$.

\section{Safe management of health care waste during COVID-19}

Best practices for safely managing health-care waste should be followed, including assigning responsibility and sufficient human and material resources to segregate and dispose of waste safely. There is no evidence that direct, unprotected human contact during the handling of health-care waste has resulted in the transmission of the COVID-19 virus. All health-care waste produced during patient care, including those with confirmed COVID-19 infection, is considered to be infectious (infectious, sharps and pathological waste) and should be collected safely in clearly marked lined containers and sharp safe boxes. This waste should be treated, preferably on-site, and then safely disposed. If waste is moved off-site, it is critical to understand where and how it will be treated and disposed. Waste generated in waiting areas of health-care facilities can be classified as non-hazardous and should be disposed in strong black bags and closed 
completely before collection and disposal by municipal waste services. All those who handle health-care waste should wear appropriate PPE (boots, long-sleeved gown, heavy-duty gloves, mask, and goggles or a face shield) and perform hand hygiene after removing it. The volume of infectious waste during the COVID 19 outbreak is expected to increase, especially through the use of PPE. Therefore, it is important to increase capacity to handle and treat this health-care waste. Additional waste treatment capacity, preferably through alternative treatment technologies, such as autoclaving or high temperature burn incinerators, may need to be procured and systems may need to be put in place to ensure their sustained operation. There is no reason to empty latrines and holding tanks of excreta from suspected or confirmed COVID-19 cases unless they are at capacity. In general, the best practices for safely managing excreta should be followed. Latrines or holding tanks should be designed to meet patient demand, considering potential sudden increases in cases, and there should be a regular schedule for emptying them based on the wastewater volumes generated. PPE (long-sleeved gown, gloves, boots, masks, and goggles or a face shield) should be worn at all times when handling or transporting excreta offsite, and great care should be taken to avoid splashing. For crews, this includes pumping out tanks or unloading pumper trucks. After handling the waste and once there is no risk of further exposure, individuals should safely remove their PPE and perform hand hygiene before entering the transport vehicle. Soiled PPE should be put in a sealed bag for later safe laundering. Where there is no off-site treatment, insitu treatment can be done using lime. Such treatment involves using a $10 \%$ lime slurry added at 1-part lime slurry per 10 parts of waste ${ }^{9}$.

\section{Safe management of dead bodies during COVID-} 19

While the risk of transmission of COVID-19 from handling the body of a deceased person is low, health care workers and others handling dead bodies should apply standard precautions at all times. Health care workers or mortuary staff preparing the body should wear: scrub suit, impermeable disposable gown (or disposable gown with impermeable apron), gloves, mask, face shield (preferably) or goggles, and boots. After use, PPE should be carefully removed and decontaminated or disposed as infectious waste as soon as practicable and hand hygiene should be performed. The body of a deceased person confirmed or suspected to have COVID-19 should be wrapped in cloth or fabric and transferred as soon as possible to the mortuary area ${ }^{9}$.

\section{Guidance on management of household waste in COVID-19 cases}

- An individual waste bag should be placed in the patient's room.

- Paper tissues and face masks used by the patient should be immediately put in the waste bag that was placed in the patient's room.

- Gloves and face masks used by the caretaker and by the cleaner should be immediately put in a second waste bag, placed near the door to the patient's room, when the caretaker or cleaner leave.

- The waste bags should be closed before they are removed from the patient's room and replaced frequently; they should never be emptied in another bag.

- These waste bags can be collected together and placed in a clean general garbage bag; the closed patient waste bags can be put directly in the unsorted garbage. No special collection activity or other disposal method is necessary.

- After handling waste bags, strict hand hygiene should be performed: use water and soap or alcohol based hand disinfectants ${ }^{10}$.

\section{Impacts of Corona Virus on Solid Waste Management}

Regulated medical waste will be produced from the COVID-19 outbreak, which may include needles, sharps, material contaminated with bodily fluids (like gauze, gloves or gowns) and pathological wastes. These wastes are regulated federally by the Occupational Safety and Health Administration 
(OSHA) for safe handling and the Department of Transportation for transportation as well as at the state level for the management and treatment of these materials before disposal.

According to the U.S. Centers for Disease Control and Prevention (CDC), risk of catching COVID-19 is higher for people who are in close contact with someone who already has the disease. The virus is thought to spread mainly through respiratory droplets (not truly airborne) produced when an infected person coughs or sneezes. It also may be possible that a person can get COVID-19 by touching a surface or object that has the virus on it and then touching their own mouth, nose or possibly their eyes, but this is not thought to be the main way the virus spreads.

However, OSHA states that without sustained human-to-human transmission, most American workers are not at significant risk of infection. Exposure risk may be elevated for some workers, including those involved in solid waste and wastewater management.

The CDC has determined that medical waste generated in the treatment of COVID-19 patients and patients under investigation (PUIs) be managed in accordance with routine procedures.

According to CDC, waste generated in the care of PUIs or patients with confirmed COVID-19 does not present additional considerations for wastewater disinfection in the U.S. Coronaviruses are susceptible to the same disinfection conditions in community and healthcare settings as other viruses, so current disinfection conditions in wastewater treatment facilities are expected to be sufficient ${ }^{11}$.

\section{Guidelines for handling of waste generated during COVID-19 patient's treatment}

Guidelines are based on current knowledge on COVID-19 and existing practices in management of infectious waste generated in hospitals while treating viral and other contagious diseases like HIV, $\mathrm{H} 1 \mathrm{~N} 1$, etc. According to the guidelines, healthcare facilities having isolation wards for COVID-19 patients need to keep separate color coded bins/ bags/containers in wards and maintain proper segregation of waste.
As precaution double layered bags (using 2 bags) should be used for collection of waste from COVID-19 isolation wards so as to ensure adequate strength and no-leaks. Collect and store biomedical waste separately prior to handing over the same to Common Bio-medical Waste Treatment and Disposal Facility (CBWTF). Use a dedicated collection bin labelled as 'COVID-19' to store COVID-19 waste and keep separately in temporary storage room prior to handing over to authorize staff of CBWTF. Biomedical waste collected in such isolation wards can also be lifted directly from ward into CBWTF collection van.

In addition to mandatory labelling, bags/containers used for collecting biomedical waste from COVID19 wards, should be labelled as 'COVID-19 Waste, it said adding that general waste not having contamination should be disposed as solid waste as per Solid Waste Management Rules, 2016.

Maintain separate record of waste generated from COVID-19 isolation wards. Use dedicated trolleys and collection bins in COVID-19 isolation wards. A label 'COVID-19 Waste' to be pasted on these items also. The (inner and outer) surface of containers/bins/trolleys used for storage of COVID19 waste should be disinfected with 1 per cent sodium hypochlorite solution daily ${ }^{12}$.

\section{Conclusion}

If the massive amount of medical wastages cannot be managed through maintaining proper and adequate guidelines, chances of community-based spreading of COVID-19 can exceed the limit and take more lives in the upcoming days.

\section{References}

1. Amid COVID-19, biomedical waste turning more hazardous: The Financial Express: access on: 25/03/2020: Available at: https://thefinancialexpress.com.bd/health/am id-covid-19-biomedical-waste-turning-morehazardous-1586504008.

2. Waste management an essential public service in the fight to beat COVID19:United Nation Environment Programee: 
access on: 29/03/2020: Available at: https://www.unenvironment.org/news-andstories/press-release/waste-managementessential-public-service-fight-beat-covid-19

3. Impacts of COVID-19 on solid waste management: Colorado Department of Public Health and Environment: access on: 04/05/2020 Available at: https://www.colorado.gov/pacific/cdphe/imp acts-covid-19-solid-waste-management

4. Can Bangladesh cope with covid-19 medical waste: The Daily Star: access on: 04/05/2020 Available at: https://www.thedailystar.net/opinion/news/c an-bangladesh-cope-covid-19-medicalwaste-1897327

5. Untreated medical waste: A serious threat to public health: The Daily Star: access on: 28/10/2019 Available at: https://www.thedailystar.net/frontpage/news/ untreated-medical-waste-serious-threatpublic-health-1819624.

6. Disposal of medical waste remains a big concern: The Daily Star: access on: 30/10/2019.

7. The COVID-19 pandemic is generating tons of medical waste: The Verge: access on: 01/05/2020 Available at: https://www.theverge.com/2020/3/26/21194 647/the-covid-19-pandemic-is-generatingtons-of-medical-waste

8. Covid-19: A Letter Concerning Hazardous Waste Management: International Solid Waste Association: access on: 02/05/2020 Available at: https://www.iswa.org/home/news/newsdetail/article/covid-19-and-hazardous-wastemanagement/109/

9. Water, sanitation, hygiene, and waste management for the COVID-19 virus: $W H O$ and UNICEF: access on: 29/04/2020: Available at: https://apps.who.int/iris/bitstream/handle/10 665/331846/WHO-2019-nCoVIPC_WASH-2020.3-eng.pdf
10. Waste management in the context of the coronavirus crisis: European Commission. Available at: https://ec.europa.eu/info/sites/info/files/wast e_management_guidance_dg-env.pdf

11. Coronavirus Impacts Hit Solid Waste Managers, Generators: Waste 360: access on: 10/05/2020 Available at: https://www.waste360.com/medicalwaste/coronavirus-impacts-hit-solid-wastemanagers-generators

12. Guidelines issued for handling of waste generated during COVID-19 patient's treatment: The Economic Times: access on: 11/05/2020 Available at: https://economictimes.indiatimes.com/news/ politics-and-nation/guidelines-issued-forhandling-of-waste-generated-during-covid19-patientstreatment/articleshow/75264399.cms?from= mdr. 